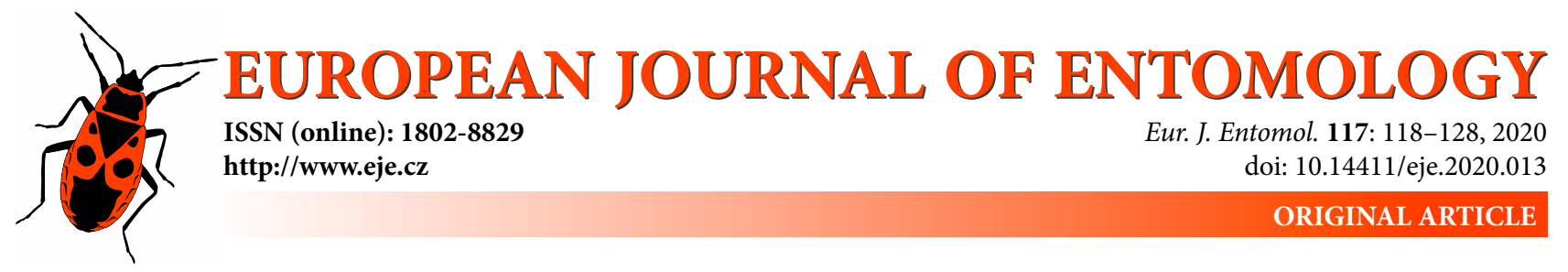

\title{
Contribution of population-level phenotypic plasticity to the invasiveness of Zaprionus indianus (Diptera: Drosophilidae)
}

\author{
Nicolás José LAVAGNinO, Marcos IMBERTI, Nicolás FlAibANI, Victoria Estefanía ORTIZ and Juan José FANARA \\ Laboratorio de Evolución, Departamento de Ecología, Genética y Evolución, Facultad de Ciencias Exactas y Naturales, \\ Universidad de Buenos Aires, IEGEBA-CONICET, Ciudad Universitaria, Pabellón II, Buenos Aires 1428, Argentina; \\ e-mails: nlavagnino@gmail.com, paicos@gmail.com,n.flaiba@gmail.com, vicrotas@gmail.com, juan_jose_fanara@yahoo.com
}

Key words. Diptera, Drosophilidae, Zaprionus indianus, phenotypic plasticity, life history traits, morphological traits, invaded range, native range

\begin{abstract}
Zaprionus indianus is a species of fly native to the Afrotropical biogeographic region, which around twenty years ago invaded the American continent. Several studies have shown that local adaptation and phenotypic plasticity of an invasive species in its native range could favour the colonization of new environments. Zaprionus indianus is a holometabolous generalist polyphagous species that breeds and feeds on the fruits of several different species, which constitute different environments. In this context, we performed a comparative analysis of the phenotypic plasticity of morphological and life history traits in response to seven different breeding environments (i.e. different breeding fruits). The comparison was of native (Africa) vs. invaded range (South America) wild-derived populations. The population-level phenotypic plasticity values related to heterogeneity in different breeding environments for most traits analysed were higher for one of the native range population. This differentiation was also recorded for the ranking across breeding environments of developmental time and wing length mean phenotypic values. In addition, mean phenotypic values pooled across fruit treatments were larger for individuals from the invaded range, which suggests local adaptation. Results define a scenario in which, although not for all the populations analysed, phenotypic plasticity contributes to the invasiveness and local adaptation in native range population of $Z$. indianus.
\end{abstract}

\section{INTRODUCTION}

There is evidence that biological invasions involving phylogenetically distant taxa are rapidly increasing (Ricciardi \& Atkinson, 2004; van Kleunen et al., 2010; Blackburn et al., 2011; Pimentel, 2011; Seebens et al., 2017). The proliferation of alien invasive species provides a unique opportunity to study ecological and evolutionary causes and consequences of a biological invasion. In this sense, numerous studies dealing with the role of phenotypic plasticity in biological invasions have shown that this mechanism could favour the colonization of new environments (Richards et al., 2006; Hulme, 2008; Zenni et al., 2014). Moreover, intraspecific comparative studies have shown that populations in the invaded range of an invasive species are more plastic than are native range populations, and this could facilitate the invasion process (Kaufman \& Smouse, 2001; Sexton et al., 2002; Parker et al., 2003). The most generally accepted concept of phenotypic plasticity is that a single genotype can produce alternative phenotypes under different environmental conditions (Schlichting \& Pigliucci, 1998). Nevertheless, a broader understanding of phenotypic plasticity does not limit it to being only a characteristic of single genotypes. In this sensu lato conceptualization, any phenotypic change in a biological entity induced by the environment is legitimately considered as phenotypic plasticity and thus it includes the plastic responses of populations and species in their particular ecological contexts (see for example Pigliucci, 2001; Valladares et al., 2006; Gianoli \& Vallarades, 2012; Forsman, 2015). For example, plastic responses of trait-mediated interactions among plants may allow them to adjust to the composition of their communities, promoting coexistence and community diversity (Callaway et al., 2003). It has also been shown that different levels of phenotypic plasticity at the population level in Mediterranean oaks favour their survival in fragmented habitats (Balaguer et al., 2001; Gratani et al., 2003). Therefore, the sensu lato consideration of phenotypic plasticity allows to evaluate this mechanism's relevance in ecological and phylogenetic contexts (Miner et al., 2005; Richards et al., 2006). Also, since this framework is suitable for comparisons of the magnitude and composition of phenotypic plasticity among populations or species it is possible to determine its role in adaptation or invasiveness by means of comparative studies. 
Zaprionus indianus Gupta, 1970 is a species of fly native to the Afrotropical biogeographic region (Chassagnard \& Kraaijeveld, 1991; Yassin et al., 2008a, b), which about 40 years ago begun to extend its geographical distribution from its native range in Africa to other areas in the world (Commar et al., 2012). In South America it was found for the first time in São Paulo city area near the Atlantic coast of Brazil in 1999 (Vilela, 1999). Since then, Z. indianus has been also detected in North and Central America (van der Linde et al., 2006; Castrezana, 2007, 2011; Renkema et al., 2013; Joshi et al., 2014; Markow et al., 2014; Van Timmeren \& Isaacs, 2014; Lasa \& Tadeo, 2015; Holle et al., 2019). In South America it has been found in Ecuador (Acurio \& Rafael, 2009), in many states of Brazil, both north and south from the initial point of detection (Castro \& Valente, 2001; De Toni et al., 2001; Vilela et al., 2001; Santos et al., 2003; Tidon et al., 2003; Kato et al., 2004; Leao \& Tidon, 2004; Chaves \& Tidon, 2008; Furtado et al., 2009; Oliveira et al., 2009; Fernandes Rodrigues \& Araújo, 2011; Pasini \& Link, 2011; Ribeiro Barbosa et al., 2012; Poppe et al., 2014; Ferreira Mendes et al., 2017; Vasconcelos et al., 2017), and further south in Paraguay (Benítez Díaz, 2015), Uruguay (Goñi et al., 2001, 2002) and Argentina (Soto et al., 2006; Lavagnino et al., 2008). The most robust hypotheses about the introduction and subsequent spread of $Z$. indianus on the American continent points to human activity, more precisely fruit trade (Tidon et al., 2003; Galego \& Carareto, 2007). Zaprionus indianus is classified as a category $\mathrm{E}$ invasive species according to Blackburn et al. (2011), since it is fully invasive, with individuals dispersing, surviving and reproducing at multiple sites in many habitats.

An important characteristic of $Z$. indianus is that, both in its native and invaded ranges, it can use a wide variety of decaying fruit as breeding and feeding resources (Lachaise \& Tsacas, 1983; Goñi et al., 2002; van der Linde et al., 2006; Schmitz et al., 2007; Lavagnino et al., 2008) what makes it a generalist polyphagous species (Aluja \& Mangan, 2007). The different breeding resources represent different environmental patches where individuals spend their embryonic and larval stages. Due to its particular ecological characteristics, $Z$. indianus provides a unique opportunity to investigate the role of phenotypic plasticity in its invasion of the American continent. Studies on the phenotypic plasticity of $Z$. indianus have mainly focused on plastic responses of individual genotypes to changes in rearing temperature (Karan et al., 1999; Loh \& Bitner Mathé, 2005; Loh et al., 2008; Bitner-Mathé \& David, 2015). These studies have detected differences in phenotypic plasticity due to thermal variation and only focus on either invaded or native ranges. Testing hypotheses on what determines the invasiveness of a given species requires comparison of populations of the species in different stages of the invasion process (van Kleunen et al., 2010), for example those in the native range with those that invaded other areas. In this sense, we have performed an intraspecific comparison between native range (Africa) and invaded range (South America) wild-derived populations of $Z$. indianus focusing on nutrient plasticity. Specifically, we compared sensu lato phenotypic plasticity and adaptive responses of morphological and life history traits of flies reared in 7 different fruit diets. Our main hypothesis is that $Z$. indianus wild-derived populations from the invaded range will differ in the magnitude and composition of morphological and life history traits phenotypic plasticity when reared on different fruit. The prediction is that larger values of plasticity and different plastic response profiles recorded in populations in invaded ranges indicate a significant contribution of population-level phenotypic plasticity in determining the invasiveness of $Z$. indianus. Also, we tested the adaptive hypothesis, which states that under the adverse environmental conditions in the habitats in invaded ranges, organisms that mature early, i.e. have shorter developmental times, have a negative cost in terms of fitness associated with a reduction in body size, which has an adverse effect on fertility (Roff, 1992; Stearns, 1992). Our related prediction is that natural selection favoured longer developmental times and large morphological traits in populations from the invaded range in South America.

\section{MATERIALS AND METHODS}

\section{Collection sites and establishment of laboratory cultures}

Zaprionus indianus flies were collected from two populations in its invaded range in South America and two populations in its native range in Africa (Fig. 1). South American populations were collected by the authors at Yuto (Province of Jujuy, Argentina, coordinates: $23^{\circ} 35^{\prime} 2.1^{\prime \prime}$ South, 61 ${ }^{\circ} 51^{\prime} 1.6^{\prime \prime}$ West) in 2011 and Montecarlo (Province of Misiones, Argentina, coordinates: $26^{\circ} 33^{\prime} 43.2^{\prime \prime} \mathrm{S}, 54^{\circ} 40^{\prime} 15.4^{\prime \prime} \mathrm{W}$ ) in 2008 . African populations were collected by other researchers at Yokadouma (Cameroon, coordinates: $3^{\circ} 31^{\prime} 47.9^{\prime \prime} \mathrm{N}, 15^{\circ} 3^{\prime} 14.3^{\prime \prime} \mathrm{E}$ ) in 2004 and Lujeri (Malawi, coordinates: $16^{\circ} 1^{\prime} 60.0^{\prime \prime} \mathrm{S}, 35^{\circ} 39^{\prime} 60.0^{\prime \prime} \mathrm{E}$ ) in 2009 from the wild and then donated to the National Drosophila Species Stock Centre (blogs.cornell.edu/drosophila). We obtained African cultures from the Stock Centre (Yokadouma: DSSC stock number: 500011031.02; Lujeri: DSSC stock number: 50001-1031.07). The four cultures were set up by massive breeding using the offspring of several $Z$. indianus single gravid females collected in the wild. Thus, these cultures represent wild-derived populations of $Z$. indianus and are equivalent samples of the natural genetic variation in each population. All cultures were maintained by full-sib mating for more than 20 generations before the experiments in the first half of 2012. The cultures were kept in 300-ml bottles, 4 bottles per population and fed a standard fly laboratory medium of cornmeal-sugar-agar and never exposed to a growth medium containing fruit (see below). Density was controlled by maintaining cultures stocks with $\sim 50$ adults per bottle as recommended for Z. indianus laboratory breeding to avoid negative effects of high population density on developing larvae (David et al., 2006b). All lines were kept at all times under controlled conditions of $25 \pm$ $1{ }^{\circ} \mathrm{C}, 60-70 \%$ of humidity and $12 \mathrm{~L}: 12 \mathrm{D}$ photoperiod.

\section{Experimental design}

Zaprionus indianus were reared on one of seven different media that included different semi-natural fruit. Approximately 100 pairs of mature flies from each of the four cultures were each placed in separate oviposition chambers for $8 \mathrm{~h}$ where the females laid eggs in a $10 \mathrm{~cm}$ Petri dish containing $10 \mathrm{ml}$ of $2.5 \%$ agar. Then, the eggs were left to hatch and 16 first-instar larvae were transferred to individual vials containing $5 \mathrm{ml}$ of one of the 


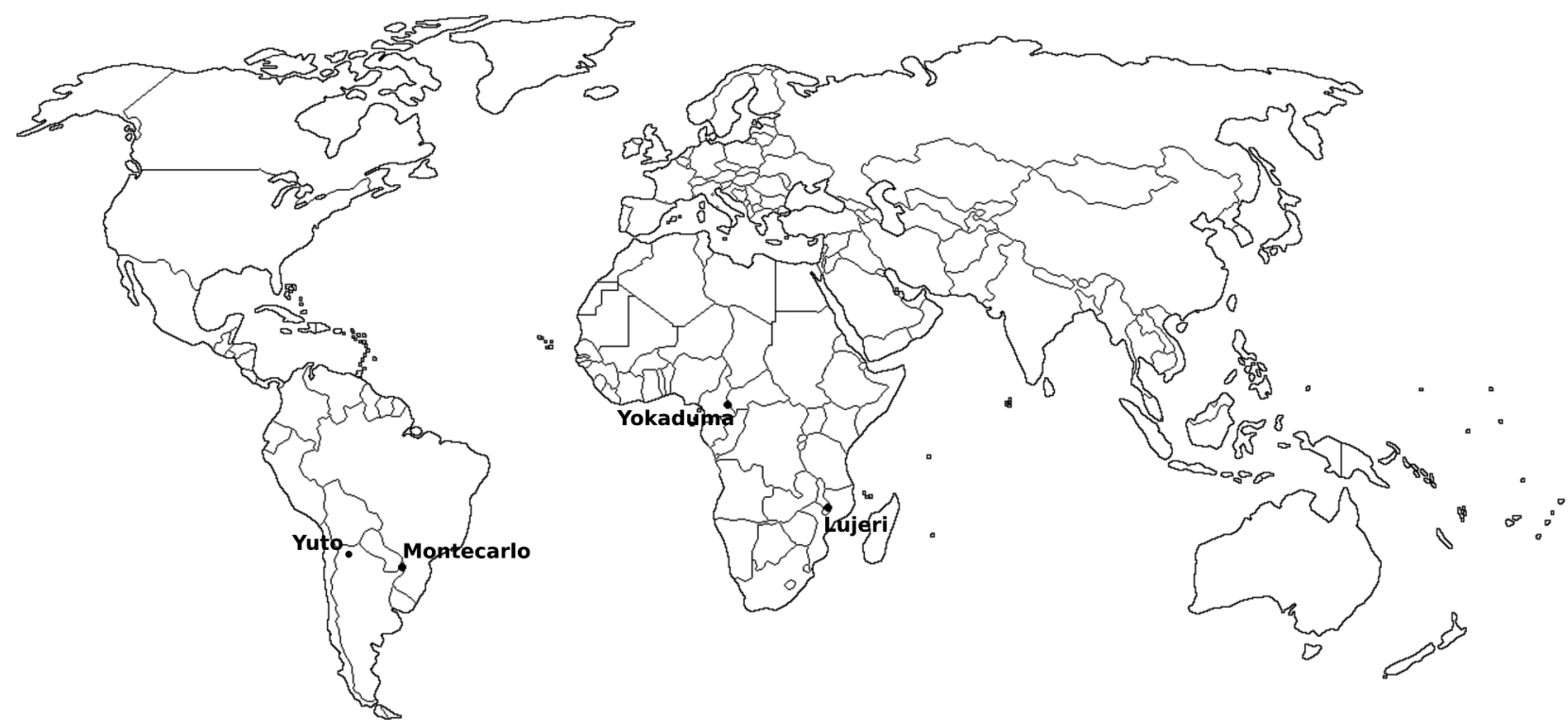

Fig. 1. Geographical locations on a world-map of the populations of Z. indianus analysed. Yokadouma (Cameroon) and Lujeri (Malawi) are in the native range of this fly on the African continent and Montecarlo (Argentina) and Yuto (Argentina) are in the invaded range at southern latitudes on the American continent.

semi-natural fruit media. These media consisted of a mixture of fruit pulp and $5.10^{-3} \mathrm{~g} / \mathrm{ml}$ agar. The fruit pulp consisted of fruit liquefied in $1 / 5 \mathrm{H}_{2} \mathrm{O}_{\mathrm{d}}$. The fruit used were: Diospyros kaki (L.) ('kaki'), Mangifera indica (L.) ('mango'), Pyrus communis (L.) ('pear'), Psidium guajava (L.) ('guava'), Carica papaya (L.) ('papaya'), Prunus persica (L.) ('peach') and Citrus sinensis (Osbeck) ('orange'). Each of the different fruit media provided a different breeding environment. These fruit are present on the both continents from where $Z$. indianus flies were obtained for experiments (Morton, 2013). Five replicates were set up per culture per semi-natural fruit medium. Flies were reared in controlled conditions at a temperature of $25^{\circ} \mathrm{C} \pm 1$, humidity of $60-70 \%$ and a photoperiod (12L: 12D). Flies that emerged from each vial were collected every $12 \mathrm{~h}$ and sorted by sex.

\section{Quantification of phenotypic traits}

Life history traits: developmental time (DT) was estimated as the time elapsed in hours from $t_{0}$ until $t_{e}$, where $t_{0}$ is the time point exactly half way between the time the adults were put in the oviposition chambers and the first-instar larvae were transferred to the vials and $t_{e}$ is the time point exactly half way between when the adult flies emerged and were collected and the last time the vial was checked. Viability (V) is the percentage of the total number of first-instar larvae transferred to vials that completed their development to the adult stage. Differentiation based on sex cannot be measured for this trait, because it is not possible to determine the sex of the larvae when they are transferred to the vials.

Morphological traits: two flies of each sex were randomly taken from each replicate for measurement. Head, wings and thorax of each individual were removed and placed on a slide in their relative positions, except for the thorax, which was placed on its side. Images of all body parts were taken under a binocular microscope $(10 \times)$ using a digital camera connected to a computer. Morphological traits of these digital images were measured using TpsDig software (Rohlf, 2001). Traits measured were: wing length (WL), wing width (WW), thorax length (TL), inter-ocular distance (ID) and head width (HW). Morphological traits in the images were quantified in terms of pixels, which were then converted to millimetres $(\mathrm{mm})$. All measurements are shown in $\mathrm{mm} \times 100$. These measurements are commonly used for quantifying the morpho- logical traits of drosophilids (Norry et al., 1994; David et al., 2006a, b; Carreira et al., 2009, 2016; Lavagnino et al., 2019).

\section{Statistical analysis}

Analytical and descriptive analyses of phenotypic variation and plasticity of morphological and life history traits of $Z$. indianus were carried out using R software (R Core Team, 2016). First, the analytical analyses using generalized linear mixed models (GLMM) were done using the lme 4 package (Bates et al., 2015). Models were constructed using the phenotypic values of each trait as variables and Origin [native range (Africa) vs. invaded range (South America)], Sex and Fruit (all 7 semi-natural media) as fixed effects and Population (Origin) (the four populations analysed) as random effects nested in Origin. All variables except viability were modelled with a normal distribution. Viability was modelled with a binomial error distribution and a logit link function (Zuur et al., 2009) using the lme4 package (Bates et al., 2015). Over dispersion was corrected for by including a random variable at the level of observations (Harrison, 2014). Wald chi-squared tests were used to test significance of fixed effects using the car package (Fox \& Weisberg, 2019). Likelihood ratio tests were used to test the significance of random factors, for each factor the full model (including fixed and random factors) was compared with the reduced model (without the random factor). Multiple testing was corrected using FDR correction (Benjamini \& Hochberg, 1995). A significant effect of Origin indicates that mean phenotypic values for individuals derived from the invaded range in South America differed from those from its native range in Africa without differentiating for the others factors. A significant Population (Origin) effect means that the mean phenotypic values of the trait analysed across breeding fruits and sexes differed between populations. If the Fruit effect is significant, it means that population mean phenotypic values for this trait varies significantly depending on which host fruit the flies were bred and our biological interpretation is that population-level phenotypic plasticity for different breeding resources exist. This is based on all cultures being equivalent samples of the natural genetic variation in each population and that the other environmental factors were controlled for. Since the plastic response is for a sample of similar genotypes within each population (each 
culture), we refer to it as population-level phenotypic plasticity. This conceptualization and estimate of plasticity is used in other studies (Pigliucci, 2001; Einhorn, 2005; Valladares et al., 2006; Gianoli \& Vallarades, 2012; Forsman, 2015). In the cases where the interaction Population (Origin) $\times$ Fruit was significant it means that population-level phenotypic plasticity varies between populations. If Origin $\times$ Fruit is also significant, it indicates that phenotypic plasticity changes tend to be more similar for populations from the same origin than for those from the other continent A significant Sex term is interpreted as the existence of sexual dimorphism, and significant interactions of Sex with the other effects represent variations in sexual dimorphism in relation to the origin of the flies, the population and fruit.

Secondly, descriptive analyses were carried out to compare the magnitude of phenotypic plasticity between populations. We used two quantitative estimators of population-level phenotypic plasticity for each trait analysed and fruit: Coefficient of Variation among the environments based on means $\left(\mathrm{CV}_{\mathrm{m}}\right)$ and Phenotypic Plasticity Index based on the maximum and minimum medians $\left(\mathrm{PI}_{\mathrm{md}}\right) . \mathrm{CV}_{\mathrm{m}}$ differences between populations were defined by a descriptive criterion, which indicates there is an inter-population difference if a $\mathrm{CV}_{\mathrm{m}}$ value of population $x$ falls outside the $\mathrm{CV}_{\mathrm{m}}$ $95 \%$ confidence interval of population $y$, and the reciprocal is also true; i.e., $\mathrm{CV}_{\mathrm{m}}$ value of population $y$ falls outside the confidence interval of population $x . \mathrm{CV}_{\mathrm{m}} 95 \%$ confidence intervals were estimated for each trait for each of the four populations studied. Intervals were estimated by means of a quantile function in the stasts package. $\mathrm{PI}_{\mathrm{md}}=$ (maximum median - minimum median $)$ / maximum median); where maximum and minimum refers to the median phenotypic value for a population reared on a particular fruit, that is the largest or smallest for all the media used (Valladares et al., 2006). Finally, to compare if the composition of phenotypic plasticity varied among populations, rankings of mean phenotypic values of viability, developmental time and wing length in different breeding treatments were constructed and compared among populations. Wilcoxon ranked sum nonparametric tests for independent samples were performed for all pairs of populations.

\section{RESULTS}

\section{Mean phenotypic values for life history and morphological traits from native and invaded range populations}

Wild-derived $Z$. indianus flies from native range populations in Africa developed significantly faster than flies derived from the invaded range in South America, with the mean developmental times of African and south American flies being 312 and $330.76 \mathrm{~h}$, respectively (Table 1, significant Origin effect). African derived flies developed $5.66 \%$ faster. Also, developmental time differed significantly between populations regardless of shared origin (Table 1, significant Population (Origin) effect; Table S1). In contrast, flies from both origins had similar values for viability (Table 1, non-significant Origin effect). Overall for all the different kinds of fruit used, $77 \%$ of the African larvae completed development to the adult stage and $78 \%$ of the South American larvae. Finally, mean values for all morphological traits were significantly larger for individuals derived from the invaded range than for those from the native range, with the exception of thorax length that had a p-value of 0.0511 for the effect of Origin (Table 1, S1).
In fact, morphological traits of South American flies were between $6.5 \%$ and $6.8 \%$ larger than those of African flies.

\section{Population-level phenotypic plasticity in life history and morphological traits of $Z$. indianus}

Results show that the mean values of each trait for the populations varied significantly depending on which fruit the flies were reared on (Table 1, significant Fruit effect). However, the significant Population (Origin) $\times$ Fruit interaction revealed significant differences in the phenotypic plasticity between populations (Table 1). When considering flies derived from different origins without distinguishing between populations, differences in phenotypic plasticity in response to breeding fruit are not maintained for most traits (Table 1, non-significant Origin $\times$ Fruit effect), with the exception of viability (Table 1 , significant Origin $\times$ Fruit effect). This means that the plastic responses for developmental time and morphological traits of native range populations did not differ in the same way from those of invaded range populations. While for viability, plastic responses between breeding fruits vary in a similar way for African populations and differently from American populations (see Table S1). Thus, the pattern of population-level phenotypic plasticity variation between populations from both ranges is quite complex and will be addressed in the following section.

Sexual dimorphism was recorded for all traits when sexes could be measured separately (Table 1, significant Sex effect). In general, females developed faster (mean DT of females was $311.88 \mathrm{~h}$ and of males $330.87 \mathrm{~h}$ ) and were smaller independently of their origins or the fruit they were reared on. Developmental time of females was $6.1 \%$ faster than that of males and males were $4.7 \%$ to $4.8 \%$ larger than females for all morphological traits. This dimorphism was independent of origin and the fruit flies were reared on. With the exception of developmental time, that significant Origin $\times$ Sex interaction, showing faster development for flies populations form Africa (Table 1).

Table 1. Summary table of GLMM analyses of all traits after FDR correction. V - viability, DT - developmental time, WL - wing length, WW - wing width, TL - thorax length, HW - head width, ID - inter-ocular distance. $S$ - significant factor ( $p$-value $<0.05$ ), $\mathrm{NS}$ - non-significant factor ( $p$-value $>0.05)$. NS ${ }^{*}$ - non-significant factor $(0.05<p$-value $<0.1)$. Total number of degrees of freedom for each GLMM were 247.

\begin{tabular}{lccccccc}
\hline & V & DT & WL & WW & TL & HW & ID \\
\hline Origin & NS & S & S & S & NS* & S & S \\
Population (Origin) & NS & S & NS & NS & NS & NS & NS \\
Fruit & S & S & S & S & S & S & S \\
Sex & - & S & S & S & S & S & S \\
Origin $\times$ Fruit & S & NS & NS & NS & NS & NS & NS \\
Origin $\times$ Sex & - & S & NS & NS & NS & NS & NS \\
Fruit $\times$ Sex & - & NS & NS & NS & NS & NS & NS \\
Origin $\times$ Fruit $\times$ Sex & - & NS & NS & NS & NS & NS & NS \\
Population (Origin) $\times$ Fruit & S & S & S & S & S & S & S \\
Population (Origin) $\times$ Sex & - & NS & NS & NS & NS & NS & NS \\
Population (Origin) $\times$ Fruit $\times$ Sex & - & NS & NS & NS & NS & NS & NS \\
\hline
\end{tabular}




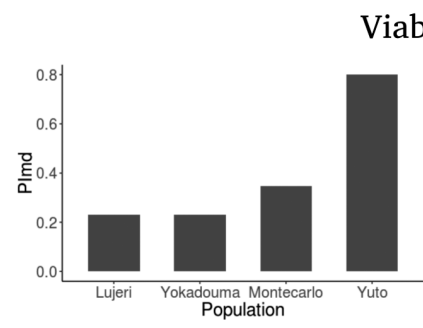

Viability

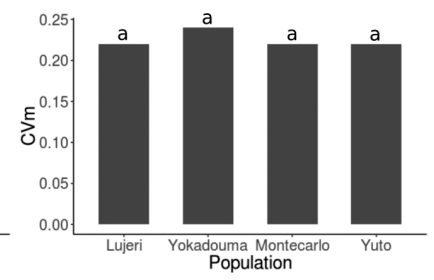

Wing Length

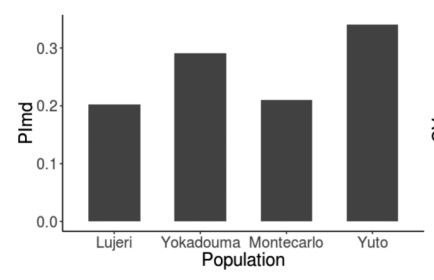

Torax Length
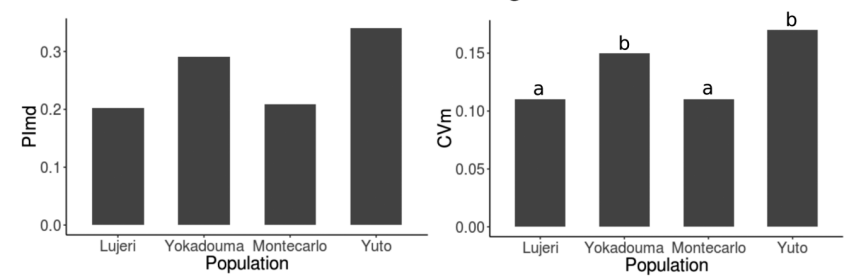

Developmental Time
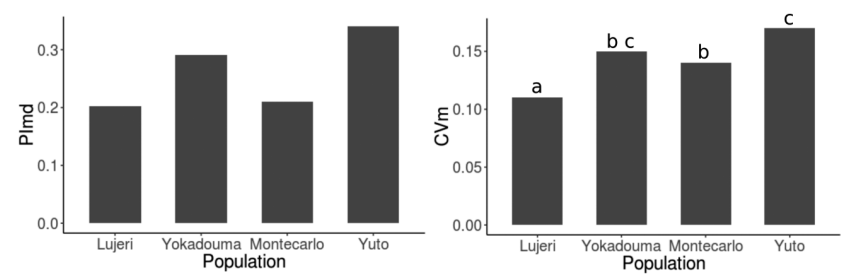

Wing Width
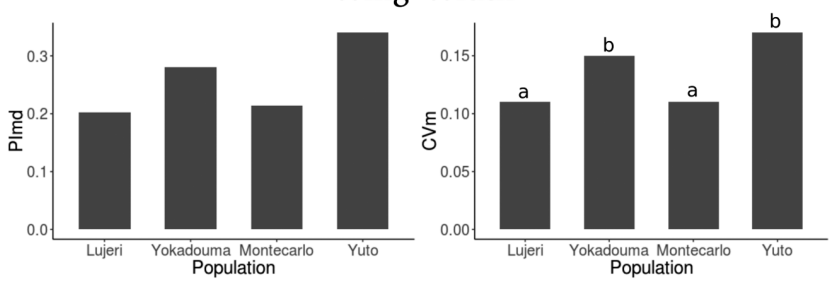

Head Width
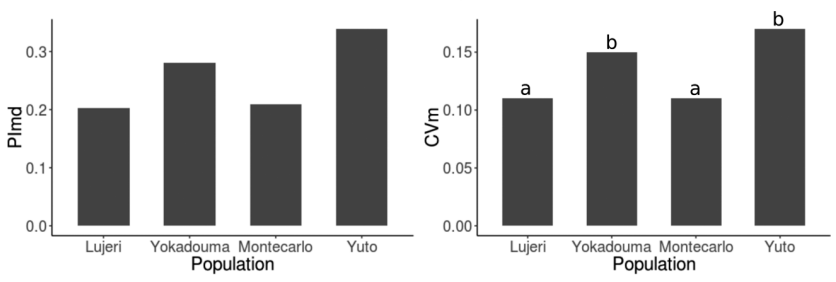

Interocular Distance
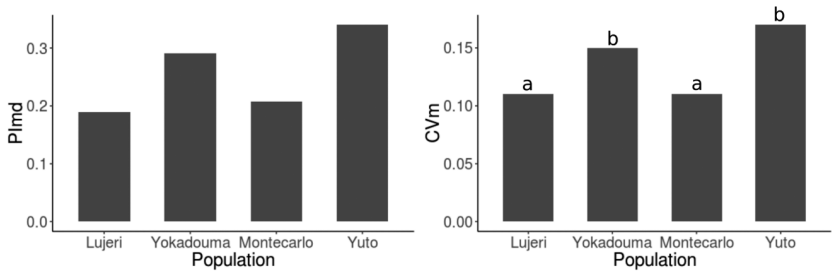

Fig. 2. Magnitude of population-level phenotypic plasticity of all traits and populations analysed independent of the type of fruit. The panels on the left show Phenotypic Plasticity Index based on maximum and minimum medians $\left(\mathrm{PI}_{\text {md }}\right)$. The panels on the right show Coefficient of Variation over the environments based on means $\left(C V_{m}\right)$ for each population. Letters indicate differences between populations evaluated by means of analytical methods, see Materials and Methods for details. Each estimation was based on 70 replicates, with the exception of viability for which 35 replicates were used.

\section{Comparison of population-level phenotypic plasticity of native and invaded range populations}

First, we compared the magnitude of phenotypic plasticity among populations using the coefficient of variation $\left(\mathrm{CV}_{\mathrm{m}}\right)$ and the Phenotypic Plasticity Index ( $\left.\mathrm{PI}_{\mathrm{md}}\right)$ as estimators (Table S2). Yuto population in the invaded range had a larger population-level phenotypic plasticity, estimated using $\mathrm{CV}_{\mathrm{m}}$, than any other population included in this study for all traits other than viability (Fig. 2). For $\mathrm{PI}_{\mathrm{md}}$, although it could not be used for comparison, the pattern of population-level phenotypic plasticity was similar since the Yuto population had the largest $\mathrm{PI}_{\mathrm{md}}$ values for all traits. The Yokadouma population in the native range had the second largest $\mathrm{PI}_{\mathrm{md}}$ values for all traits other than viability (Fig. 2). In terms of median phenotypic values associated with rearing on different fruit, these two populations both had long developmental times and were larger when reared on 'kaki' (Table S1). Then, we compared the rankings of mean phenotypic values for viability, developmental time and wing length when reared on the different fruit. The Yuto population from the invaded range differed significantly in developmental time and wing length from,
Yokadouma and Lujeri, the two populations from the native range of $Z$. indianus (Fig. 3).

\section{DISCUSSION}

Studies dealing with phenotypic plasticity in Z. indianus have focused on plastic responses caused by temperature changes (Karan et al., 1999; Loh \& Bitner Mathé, 2005; Loh et al., 2008; Bitner-Mathé \& David, 2015). This is based on the reasonable premise that temperature is one of the most important environmental determinants of development and adult lifestyle of a holometabolous insect like $Z$. indianus. However, as this species is polyphagous and uses several different kinds of fruit for breeding and feeding, it is likely that these resources are also important ecological characteristics. In this context, our results indicate that there is a difference in the magnitude and composition of population-level phenotypic plasticity associated with feeding on different types of fruit between native and invaded ranges populations of this fly. Although the phenomenon of different phenotypic plasticity between native and invaded populations was found, this may not be a general phenomenon as only the phenotypic plastic- 

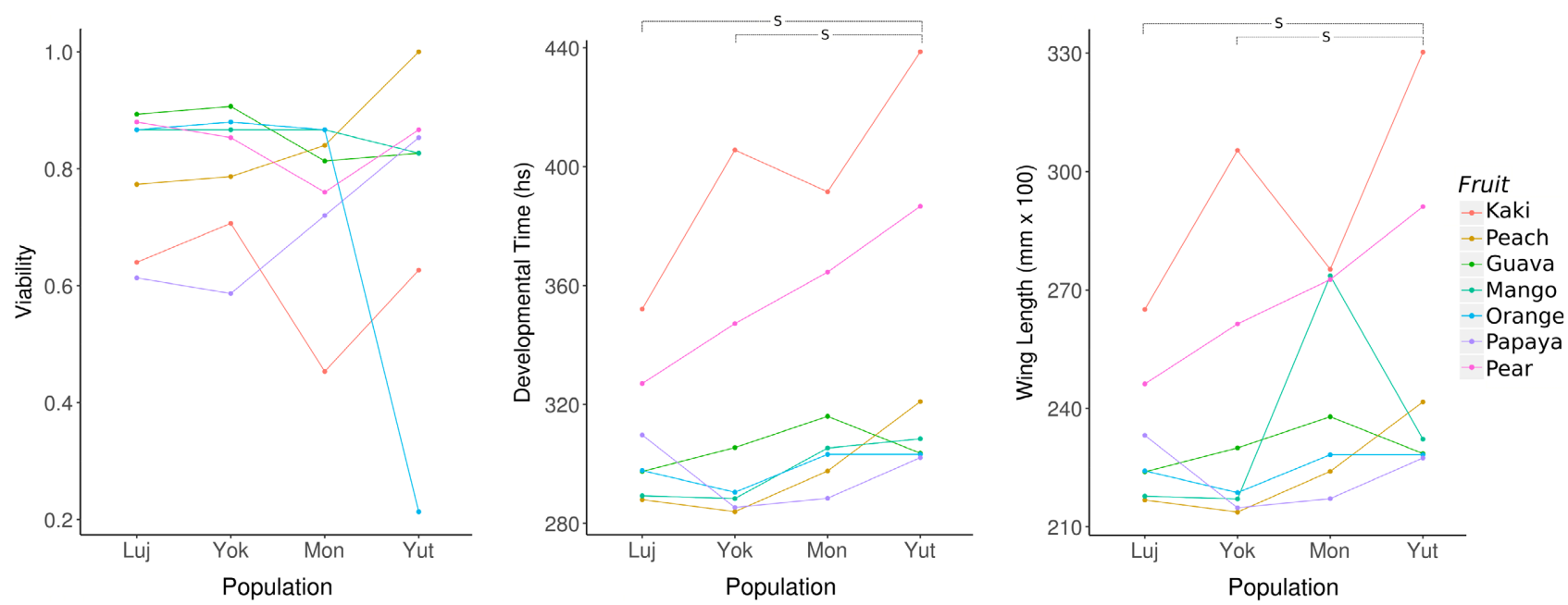

Fig. 3. Ranked profiles of mean phenotypic values for viability, developmental time and wing length of individuals reared on the different types of fruit for each population ranked from highest to lowest. Populations Lujeri (Luj) and Yokadouma (Yok) are from the native range and Montecarlo (Mon) and Yuto (Yut) from the invaded range. " $S$ " indicates a significant difference in performance ranking among populations based on Wilcoxon signed-rank tests.

ity of the Yuto population was greater than in one of the populations from native range. These differences were not found for the other invaded range population analysed, the Montecarlo population. It was also the Yuto population that had a different composition of phenotypic plasticity from both native range populations for developmental time and wing length. Differences in the composition of phenotypic plasticity were recorded in changes in the ranking of mean phenotypic values per type of fruit between populations. The lack of generality in the patterns identified could be the consequence of differences in the genetic bases of phenotypic plasticity between populations, which probably resulted from drastic demographic events during the invasion of South America. In particular, reductions in the effective population size at the time of population foundation, or population bottlenecks in subsequent generations, may have affected the expression of phenotypic plasticity. This could be the case for the particular demographic history of the native range population Montecarlo, which differed in its plasticity pattern.

The occurrence of phenotypic plasticity in invaded ranges is generally interpreted as positive for a successful invasion because it could be beneficial for coping with new and heterogeneous environments in invaded ranges (Kaufman \& Smouse, 2001; Sexton et al., 2002; Parker et al., 2003; Fordyce, 2006; Richards et al., 2006; Chun et al., 2007; Matesanz et al., 2010; Davidson et al., 2011; Zenni et al., 2014). Also, following this scenario, greater values of phenotypic plasticity are expected in the invaded range, as was recorded in the present study for the Yuto population. However, a change in the composition of phenotypic plasticity could also indicate a contribution of this mechanism to invasiveness, as was found in the changes in the ranking of phenotypic values of traits between invaded range Yuto population and African populations. All in all, these differences in phenotypic variation related to heterogeneity in breeding substrates between native and invaded range populations could be a relevant factor enabling invasive
Z. indianus to cope with new and heterogeneous environments (Sexton et al., 2002; Parker et al., 2003; Fordyce, 2006; Richards et al., 2006; Chun et al., 2007; Matesanz et al., 2010; Davidson et al., 2011; Zenni et al., 2014).

Our results revealed that all traits were sexually dimorphic when the sexes could be measured separately, with females developing faster and being smaller in terms of all the morphological traits measured. This pattern was unexpected because in most drosophilid species studied the females are larger and develop slower than males. Although previous studies on $Z$. indianus show the same expected direction for sexual dimorphism, they also indicate that the dimorphism is less marked than in other drosophilids (see Karan et al., 1999; Loh \& Bitner Mathé, 2005; BitnerMathé \& David, 2015). It is also reported that sexual dimorphism tends to disappear in laboratory cultures of $Z$. indianus (Loh \& Bitner Mathé, 2005; Loh et al., 2008). Thus, it is possible that the sexual dimorphism recorded in our study was a consequence of the semi-natural fruit medium used in laboratory breeding of the flies. This hypothesis was not tested in the present study and should be further analysed. The comparisons we made also enabled the evaluation of whether natural selection had a role in determining the invasiveness of $Z$. indianus. Mean phenotypic values pooled across the fruit treatments for most traits analysed were larger for individuals derived from the invaded range on the American continent than those derived from the native range in Africa. Exceptions to this pattern were thorax length and viability, although thorax length was marginally significant. Even if trait values are disaggregated between breeding fruit, larger phenotypic means were recorded for population in the invaded range for most morphological traits and types of fruit. For developmental time, larger values for invaded range populations were also found as a general trend. In the light of life history theory, these results could be interpreted as adaptive (Roff, 1992; Stearns, 1992). Under adverse environmental conditions, such as poor nutrients, different predators, competitors 
and/or extreme temperatures, there is a cost in terms of fitness for organisms that mature earlier, i.e. have a shorter developmental time, which is associated with a reduction in body size and fertility (Roff, 1992; Stearns, 1992). In invaded ecosystems that are different from those in the native range, it is likely that either the physicochemical or biological conditions will be unfavourable for $Z$. indianus. So, in terms of life history theory natural selection is likely to favour a longer developmental time in populations in the invaded than in native ranges. The same can be proposed for morphological traits. In concordance with our results, previous surveys also report higher values for the morphological traits of the South American populations than the African populations (David et al., 2006a, b). Nevertheless, it should be noted that differences in the phenotypic values of morphological and life history traits among populations in different environments may only indicate the action of natural selection that results in local adaptation. But as Reznick \& Travis (1996) point out, that although phenotypic differences between populations in different environments might indicate that adaptation is occurring in nature it must be confirmed by another kind of evidence. At this point, it is worth mentioning that since the populations analysed were kept in the laboratory for several generations before the experiments we cannot rule out potential effects of laboratory adaptation and genetic drift. However, given that these populations were maintained at large numbers and reared on a standard laboratory medium it is unlikely that laboratory selection and/or genetic drift or bottlenecks affected the patterns recorded. In fact, a study by Maclean et al. (2018) report that laboratory maintenance does not affect comparisons of the patterns in the traits of flies similar to those used in this study.

Several studies that compare trait values of invasive species in their invaded and native ranges report large differences (Sakai et al., 2001; Tsutsui \& Suarez, 2003; van Kleunen et al., 2010). However, few studies deal with whether the underlying mechanisms are phenotypic plasticity or adaptive evolution in the invaded range or a combination of both. In this sense, our results define a scenario in which population-level phenotypic plasticity associated with heterogeneity in breeding substrates contributes to the invasiveness of $Z$. indianus as well as local adaptation of populations in their native range. All things considered, the results hint at the coexistence of adaptation and phenotypic plasticity being relevant for $Z$. indianus invasiveness. Therefore, when it comes to understanding and explaining the invasion of $Z$. indianus of the southernmost latitudes of the American continent, it is not possible to propose that one mechanism is of greater importance than another. In fact, it seems necessary to consider the possibility that both are acting simultaneously.

AUTHORS' CONTRIBUTIONS. NJL, MI and JJF planed, designed and did the experimental work, NJL, NF and VEO analysed the data, NJL, MI, NF, VEO and JJF wrote the manuscript.

ACKNOWLEDGEMENTS. This work was supported by grants from Agencia Nacional de Promoción Científica y Tecnológica
(Argentina) (PICT 2012-0640) and Universidad de Buenos Aires (Argentina) (UBACyT 20020100100482). NJL and JJF are members of Carrera del Investigador Científico of CONICET (Argentina). MI, NF, and VEO are recipients of a scholarship from Carrera del Investigador Científico of CONICET (Argentina).

\section{REFERENCES}

Acurio A.E. \& RAFAel V.L. 2009: Inventario taxonómico de Drosophilidae (Diptera) en el Parque Nacional Yasuni amazonia ecuatoriana. — Acta Amazon. 39: 713-718.

Aluja M. \& Mangan R.L. 2007: Fruit fly (Diptera: Tephritidae) host status determination: critical conceptual, methodological, and regulatory considerations. - Annu. Rev. Entomol. 53: 473-502.

Balaguer L., Martínez-Ferri E., Valladares F., Pérez-Corona M.E., Baquedano F.J., Castillo F.J. \& Manrique E. 2001: Population divergence in the plasticity of the response of Quercus coccifera to the light environment. - Funct. Ecol. 15: $124-135$.

Bates D., Maechler M., Bolker B. \& Walker S. 2015: Fitting linear mixed-effects models using lme4. - J. Stat. Soft. 67: $1-48$.

Benítez DíAz E.A. 2015: Primer registro de la Mosca Africana del Higo, Zaprionus indianus (Diptera: Drosophilidae) en Paraguay. - Bol. Mus. Nac. Hist. Nat. Parag. 19: 100-110.

Benjamini Y. \& Hochberg Y. 1995: Controlling the false discovery rate: A practical and powerful approach to multiple testing. - J. Roy. Stat. Soc. (B) 57: 289-300.

Bitner-Mathé B.C. \& DAVID J.R. 2015: Genetic variability and phenotypic plasticity of metric thoracic traits in an invasive drosophilid in America. - Genetica 143: 441-451.

Blackburn T.M., Pyšek P., Bacher S., Carlton J.T., Duncan R.P., JarošíK V., Wilson J.R.U. \& Richardson D.M. 2011: A proposed unified framework for biological invasions. Trends Ecol. Evol. 26: 333-339.

Callaway R., Pennings S.C. \& Richards C.L. 2003: Phenotypic plasticity and interactions among plants. — Ecology 84: 115128.

Carreira V.J., Mensch J. \& Fanara J.J. 2009: Body size in Drosophila: genetic architecture, allometries and sexual dimorphism. - Heredity 102: 246-256.

Carreira V.P., Mensch J., Hasson E. \& Fanara J.J. 2016: Natural genetic variation and candidate genes for morphological traits in Drosophila melanogaster. — PLoS ONE 11: e0160069, 26 pp.

CAStrezana S. 2007: New records of Zaprionus indianus Gupta, 1970 (Diptera, Drosophilidae) in North America and a key to identify some Zaprionus species deposited in the Drosophila Tucson Stock Center. — Dros. Inf. Serv. 90: 34-36.

Castrezana S. 2011: New record on novel hosts for the drosophilid pest Zaprionus indianus. — Dros. Inf. Serv. 94: 1-2.

CAstro F.L. \& Valente V.L.S. 2001: Zaprionus indianus invading communities in the southern Brazilian city of Porto Alegre. — Dros. Inf. Serv. 84: 15-17.

Chassagnard M.T. \& Kraaijeveld A.R. 1991: The occurrence of Zaprionus sensu stricto in the Paleartic region (Diptera, Drosophilidae). - Ann. Soc. Entomol. Fr. 27: 495-496.

Chaves N.B. \& Tidon R. 2008: Biogeographical aspects of drosophilids (Diptera, Drosophilidae) of the Brazilian savanna. Rev. Bras. Entomol. 52: 340-348.

Chun Y.J., Collyer M.L., Moloney K.A. \& Nason J.D. 2007: Phenotypic plasticity of native vs. invasive purple loosestrife: a two-state multivariate approach. - Ecology 88: 1499-1512. 
Commar L.S., Galego L.G., Ceron C.R. \& Carareto C.M.A. 2012: Taxonomic and evolutionary analysis of Zaprionus indianus and its colonization of Palearctic and Neotropical regions. - Genet. Mol. Biol. 35: 395-406.

David J.R., Araripe L.O., Bitner-Mathé B.C., Capy P., Goñi B., Klaczko L.B., Legout H., Martins M.B., Vouidibio J., YasSIN A. \& Moreteau B. 2006a: Quantitative trait analysis and geographic variability of natural populations of Zaprionus indianus, a recent invader in Brazil. - Heredity 96: 53-62.

David J.R., Araripe L.O., Bitner-Mathé B.C., Capy P., GoÑ B., Klaczko L.B., Legout H., Martins M.B., Vouidibio J., Yassin A. \& Moreteau B. 2006b: Sexual dimorphism of body size and sternopleural bristle number: a comparison of geographic populations of an invasive cosmopolitan drosophilid. - Genetica 128: 109-122.

Davidson A.M., Jennions M. \& Nicotra A.B. 2011: Do invasive species show higher phenotypic plasticity than native species and, if so, is it adaptive? A meta-analysis. - Ecol. Lett. 14: 419-431.

De Toni D.C., Hofmann P.R.P. \& Valente V.L.S. 2001: First record of Zaprionus indianus (Diptera, Drosophilidae) in the State of Santa Catarina, Brazil. - Biotemas 14: 71-85.

EINHORN K.S. 2005: Growth and physiology of ash (Fraxinus excelsior) and beech (Fagus sylvatica) seedlings in response to a light gradient following natural gap formation. - Ecol. Bull. 52: $1-53$.

Fernandes Rodrigues D.R. \& Araúso E.L. 2011: Ocorrência de Zaprionus indianus Gupta (Diptera: Drosophilidae) em frutos de juazeiro Ziziphus joazeiro Mart. (Rhamnaceae) no estado do Rio Grande do Norte. - Rev. Bras. Frut. 33: 1356-1358.

Ferreira Mendes M., Berti Valer F., Aleixo Vieira J.G., Laner Blauth M. \& GotTschalk M.S. 2017: Diversity of Drosophilidae (Insecta, Diptera) in the Restinga forest of southern Brazil. - Rev. Bras. Entomol. 61: 248-256.

FoRDYCE J.A. 2006: The evolutionary consequences of ecological interactions mediated through phenotypic plasticity. - J. Exp. Biol. 209: 2377-2383.

ForSMAN A. 2015: Rethinking phenotypic plasticity and its consequences for individuals, populations and species. - Heredity 115: $276-284$.

Fox J. \& Weisberg S. 2019: An $\{R\}$ Companion to Applied Regression. $3 \mathrm{rd}$ ed. Sage, Thousand Oaks, CA, $607 \mathrm{pp}$.

Furtado I.S., Martins M.B. \& Costa J.E. 2009: First record of Zaprionus indianus (Diptera: Drosophilidae) in the Urucu Petroleum Province in Amazonas, Brazil. — Dros. Inf. Serv. 92: $17-18$.

Galego L.G.C. \& CARAReto C.M.A. 2007: Analysis of the drosophilid Zaprionus indianus introduction in Brazil: Contribution of esterase loci polymorphisms. — Dros. Inf. Serv. 90: 79-84.

Gianoli E. \& Valladares F. 2012: Studying phenotypic plasticity: the advantages of a broad approach. - Biol. J. Linn. Soc. 105: $1-7$.

Goñi B., Fresia P., Calviño M., Ferreiro M.J. \& Valente V.L.S. 2001: First record of Zaprionus indianus Gupta, 1970 (Diptera, Drosophilidae) in southern localities of Uruguay. - Dros. Inf. Serv. 84: 61-65.

GoÑI B., Martinez M.E., Techera G. \& Fresia P. 2002: Increased frequencies of Zaprionus indianus Gupta, 1970 (Diptera, Drosophilidae) in Uruguay. - Dros. Inf. Serv. 85: 75-80.

Gratani L., Meneghini M., Pesoli P. \& Crescente M.F. 2003: Structural and functional plasticity of Quercus ilex seedlings of different provenances in Italy. - Oecologia 17: 515-521.

GUPTA J.P. 1970: Description of a new species of Phorticella and Zaprionus (Drosophilidae) from India. - Proc. Indian Natl. Sci. Acad. (B) 36: 62-70.
HARRISON X.A. 2014: Using observation-level random effects to model overdispersion in count data in ecology and evolution. - PeerJ. 2: e616, 19 pp.

Holle S.G., Tran A.K., Burkness E.C., Ebbenga D.N. \& HutchISON W.D. 2019: First detections of Zaprionus indianus (Diptera: Drosophilidae) in Minnesota. - J. Entomol. Sci. 54: 99-102.

Hulme P.E. 2008: Phenotypic plasticity and plant invasions: Is it all Jack? - Funct. Ecol. 22: 3-7.

Joshi N.K., Biddinger D.J., DemchaK K. \& Deppen A. 2014: First report of Zaprionus indianus (Diptera: Drosophilidae) in commercial fruits and vegetables in Pennsylvania. - J. Insect Sci. 14: 259, 4 pp.

Karan D., Moreteau B. \& David J.R. 1999: Growth temperature and reaction norms of morphometrical traits in a tropical drosophilid: Zaprionus indianus. - Heredity 83: 398-407.

Kato C.M., Foureaux L.V., César R.A. \& Torres M.P. 2004: Occurrence of Zaprionus indianus Gupta, 1970 (Diptera: Drosophilidae) in Minas Gerais State. - Ciência Agrotecnol. 28: 454-455.

Kaufman S.R. \& Smouse P.E. 2001: Comparing indigenous and introduced populations of Melaleuca quinquenervia (Cay.) Blake: Response of seedlings to water and $\mathrm{pH}$ levels. - Oecologia 127: 487-494.

LACHAISE D. \& Tsacas L. 1983: Breeding-sites in tropical African drosophilids. In Ashburner M., Carson H.L. \& Thompson J.N. (eds): Genetics and Biology of Drosophila. Academic Press, New York, pp. 221-332.

LASA R. \& TADEO E. 2015: Invasive drosophilid pests Drosophila suzukii and Zaprionus indianus (Diptera: Drosophilidae) in Veracruz, Mexico. - Fla Entomol. 98: 987-988.

Lavagnino N.J., Carreira V.P., Mensch J., Hasson E. \& Fanara J.J. 2008: Geographic distribution and hosts of Zaprionus indianus (Diptera: Drosophilidae) in North-Eastern Argentina. Rev. Soc. Entomol. Argent. 67: 189-192.

Lavagnino N.J., Imberti M., Ortiz V.E., Flaibani N. \& Fanara J.J. 2019: Contrasting levels of genotype by environment interaction for life history and morphological traits in invasive populations of Zaprionus indianus (Diptera: Drosophilidae). - Insect $S c i$. [in press].

LEAo B.F.D. \& Tidon R. 2004: Newly invading species exploiting native host-plants: the case of the African Zaprionus indianus (Gupta) in the Brazilian Cerrado (Diptera, Drosophilidae). Ann. Soc. Entomol. Fr. 40: 285-290.

LOH R. \& BitNer-MathÉ B.C. 2005: Variability of wing size and shape in three populations of a recent Brazilian invader, Zaprionus indianus (Diptera: Drosophilidae), from different habitats. - Genetica 125: 271-281.

Loh R., David J.R., Debat V. \& Bitner-Mathé B.C. 2008: Adaptation to different climates results in divergent phenotypic plasticity of wing size and shape in an invasive drosophilid. J. Genet. 87: 209-217.

Maclean H.J., Kristensen T.N., Sørensen J.G. \& Overgaard J. 2018: Laboratory maintenance does not alter ecological and physiological patterns among species: A Drosophila case study. - J. Evol. Biol. 31: 530-542.

Markow T.A., Hanna G., Riesgo-Escovar J.R., Tellez-Garcia A.A., Richmond M.P., NazARio-Yepiz N.O., Ramírez Loustalot Laclette M., Carpinteyro-Ponce J. \& Pfeiler E. 2014: Population genetics and recent colonization history of the invasive drosophilid Zaprionus indianus in Mexico and Central America. - Biol. Invas. 16: 2427-2434.

Matesanz S., Gianoli E. \& Valladares F. 2010: Global change and the evolution of phenotypic plasticity in plants. - Ann. N.Y. Acad. Sci. 1206: 35-55. 
Miner B.G., Sultan S.E., Morgan S.G., Padilla D.K. \& Relyea R.A. 2005: Ecological consequences of phenotypic plasticity. - Trends Ecol. Evol. 20: 685-692.

Morton J.F. 2013: Fruits of Warm Climates. Echo Point Books \& Media, Vermont, $550 \mathrm{pp}$.

Norry F.M., Vilardi J.C., Fanara J.J. \& Hasson E. 1994: Courtship success and multivariate analysis of sexual selection on morphometric traits in Drosophila buzzatii (Diptera: Drosophilidae). - J. Insect Behav. 8: 219-229.

Oliveira G.F., de Melo K.P.S., Garcia A.C.L. \& Rohde C. 2009: First record of Zaprionus indianus (Diptera, Drosophilidae) in Fernando de Noronha, an Oceanic Island of Pernambuco State, Brazil. - Dros. Inf. Serv. 92: 18-20.

Parker I.M., Rodriguez J. \& LoIK M.E. 2003: An evolutionary approach to understanding the biology of invasions: Local adaptation and general-purpose genotypes in the weed Verbascum thapsus. - Conserv. Biol. 17: 59-72.

PAsini M.P.B. \& LinK D. 2011: Efficiency of different traps to capture Zaprionus indianus (Diptera: Drosophilidae) in fig orchard in Santa Maria county, Rio Grande do Sul state, Brazil. —Int. J. Agric. Sci. Soil Sci. 1: 349-354.

Pigliucci M. 2001: Phenotypic Plasticity: Beyond Nature and Nurture. Johns Hopkins University Press, Maryland, 348 pp.

Pimentel D. 2011: Biological Invasions: Economic and Environmental Costs of Alien Plant, Animal, and Microbe Species. CRC Press, Boca Raton, FL, 463 pp.

Poppe J.L., Schmitz H.J., Grimaldi D. \& Da Silva Valente V.L. 2014: High diversity of Drosophilidae (Insecta, Diptera) in the Pampas Biome of South America, with descriptions of new Rhinoleucophenga species. —Zootaxa 3779: 215-245.

Renkema J.M., Miller M., Fraser H., Légaré J.P. \& Hallett R.H. 2013: First records of Zaprionus indianus Gupta (Diptera: Drosophilidae) from commercial fruit fields in Ontario and Quebec, Canada. - J. Entomol. Soc. Ont. 144: 125-130.

Reznick D. \& Travis J. 1996: The empirical study of adaptation in natural populations. In Rose M.R. \& Lauder G.V. (eds): Adaptation. Academic Press, San Diego, pp. 243-289.

Ribeiro Barbosa M.R., Graciolli G. \& Paiva F. 2012: Diptera, Drosophilidae, Zaprionus indianus Gupta, 1970: Distribution extension for the state of Mato Grosso do Sul, Brazil. — Check List 8: 175-176.

RicCIARDi A. \& AtKInson S.K. 2004: Distinctiveness magnifies the impact of biological invaders in aquatic ecosystems. Ecol. Lett. 7: 781-784.

Richards C.L., Bossdorf O., Muth N.Z., Gurevitch J. \& PigliUCCI M. 2006: Jack of all trades, master of some? On the role of phenotypic plasticity in plant invasions. - Ecol. Lett. 9: 981-993.

R Core Team 2016: A Language and Environment for Statistical Computing. URL: http://www.R-project.org/

Roff D.A. 1992: The Evolution of Life Histories: Theory and Analysis. Chapman \& Hall, New York, 535 pp.

RoHLF F.J. 2001: tpsDig. 1.31 Version. URL: http://life.bio.sunysb.edu/morph/

Sakai A.K., Allendorf F.W., Holt J.S., Lodge D.M., Molofsky J., With K.A., Baughman S., Cabin R.J., Cohen J.E., EllSTRAND N.C. ET AL. 2001: The population biology of invasive species. - Annu. Rev. Ecol. Evol. Syst. 32: 305-332.

Santos J.F., Rieger T.T., Campos S.R.C., Nascimento A.C.C., Félix P.T., Silva S.V.O. \& Freitas F.M.R. 2003: Colonization of northeast region of Brazil by the drosophilid flies Drosophila malerkotliana and Zaprionus indianus, a new potential insect pest for Brazilian fruticulture. - Dros. Inf. Serv. 86: 83-125.

Schlichting C.D. \& Pigliucci M. 1998: Phenotypic Evolution: A Reaction Norm Perspective. Sinauer, Sunderland, 340 pp.
Schmitz H.J., Valente V.L.S. \& Hofmann P.R.P. 2007: Taxonomic survey of Drosophildae (Diptera) from mangrove forests of Santa Catarina Island, Southern Brazil. - Neotrop. Entomol. 36: $53-64$

Seebens H., Blackburn T.M., Dyer E.E., Genovesi P., Hulme P.E., Jeschke J.M., Pagad S., Pyšek P., Winter M., ArianoutSOU M. ET AL. 2017: No saturation in the accumulation of alien species worldwide. - Nat. Comm. 8: 14435,9 pp.

SeXton J.P., McKay J.K. \& Sala A. 2002: Plasticity and genetic diversity may allow saltcedar to invade cold climates in North America. - Ecol. Appl. 12: 1652-1660.

Soto I., Corio C., Fanara J.J. \& Hasson E. 2006: First record of Zaprionus indianus Gupta 1970 (Diptera, Drosophilidae) in Argentina. - Dros. Inf. Serv. 89: 13-14.

SteARNS S.C. 1992: The Evolution of Life Histories. Oxford University Press, Oxford, 249 pp.

Tidon R., Leite D.F. \& Leao B.F.D. 2003: Impact of the colonisation of Zaprionus indianus (Diptera, Drosophilidae) in different ecosystems of the Neotropical Region: 2 years after the invasion. - Biol. Conserv. 112: 299-305.

Tsutsur N.D. \& SuAREZ A.V. 2003: The colony structure and population biology of invasive ants. - Conserv. Biol. 17: 48-58.

VAlLAdARES F., SANChez-Gomez D. \& Zavala M.A. 2006: Quantitative estimation of phenotypic plasticity: bridging the gap between the evolutionary concept and its ecological applications. -J. Ecol. 94: 1103-1116.

Van der Linde K., Steck G.J., Hibbard K., Birdsley J.S., Alonso L.M. \& Houle D. 2006: First records of Zaprionus indianus (Diptera: Drosophilidae), a pest species on commercial fruits from Panama and The United States of America. - Fla Entomol. 89: 402-404.

Van Kleunen M., Dawson W., Schlaepfer D., JeschKe J.M. \& FISCHER M. 2010: Are invaders different? A conceptual framework of comparative approaches for assessing determinants of invasiveness. - Ecol. Lett. 13: 947-958.

Van Timmeren S. \& Isaacs R. 2014: Drosophila suzukii in Michigan vineyards, and the first report of Zaprionus indianus from this region. - J. Appl. Entomol. 138: 519-527.

Vasconcelos A., Azevedo T. \& Santos R.S. 2017: Primeiro registro de Zaprionus indianus Gupta (Diptera: Drosophilidae) no Estado do Acre, Brasil. — EntomoBrasilis 10: 60-63.

Vilela C.R. 1999: Is Zaprionus indianus Gupta, 1970 (Diptera: Drosophilidae) currently colonizing the Neotropical region? Dros. Inf. Serv. 82: 37-39.

Vilela C.R., Teixeira E.P. \& Stein C.P. 2001: Mosca africana do figo, Zaprionus indianus (Diptera: Drosophilidae). In Vilela E.F., Zucchi R.A. \& Cantor F. (eds): Historico e Impacto das Pragas Introduzidas no Brasil. Holos, Ribeirao Preto, pp. 48-52.

Yassin A., Araripe L.O., Capy P., Da Lage J.L., Klaczko L.B., Maisonhaute C., Ogereau D. \& David J.R. 2008a: Grafting the molecular phylogenetic tree with morphological branches to reconstruct the evolutionary history of the genus Zaprionus (Diptera: Drosophilidae). - Mol. Phylogenet. Evol. 47: 903915.

Yassin A., Capy P., Madi-Ravazzi L., Ogereau D. \& David J.R. 2008b: DNA barcode discovers two cryptic species and two geographical radiations in the invasive drosophilid Zaprionus indianus. - Mol. Ecol. Resour. 8: 491-501.

ZenNi R.D., Lamy J.B., Lamarque L.J. \& Port A.J. 2014: Adaptive evolution and phenotypic plasticity during naturalization and spread of invasive species: implications for tree invasion biology. - Biol. Invas. 16: 635-644. 
Zuur A.F., Leno E.N., Walker N.J., SAVeliev A.A. \& Smith G.M.

2009: Mixed Effects Models and Extensions in Ecology with R.

Springer, New York, 574 pp.

Received September 24, 2019; revised and accepted March 11, 2020

Published online March 24, 2020

Table S1. Mean phenotypic values and standard errors (S.E.) for each trait analysed for each population reared on a particular type of fruit. DT - developmental time, V - viability, WL - wing length, WW - wing width, TL - thorax length, ID - inter-ocular distance, HW - head width. Values are based on 10 replicates for all traits, except for $\bigvee$ for which 5 replicates were used.

\begin{tabular}{|c|c|c|c|c|c|c|c|c|c|}
\hline & & \multicolumn{2}{|c|}{ Lujeri } & \multicolumn{2}{|c|}{ Yokadouma } & \multicolumn{2}{|c|}{ Montecarlo } & \multicolumn{2}{|c|}{ Yuto } \\
\hline & & Mean & S.E. & Mean & S.E. & Mean & S.E. & Mean & S.E. \\
\hline \multirow{7}{*}{ DT (hs) } & Kaki & 352.1092 & 10.4686 & 405.6200 & 9.6578 & 391.5771 & 15.7259 & 438.6733 & 16.9262 \\
\hline & Peach & 287.9903 & 4.1033 & 283.9229 & 3.9139 & 297.6190 & 4.5899 & 320.9895 & 5.7836 \\
\hline & Guava & 297.4614 & 6.3109 & 305.5010 & 6.0429 & 316.0190 & 10.2756 & 303.6229 & 5.5346 \\
\hline & Mango & 289.2747 & 4.6165 & 288.3600 & 7.089 & 305.3352 & 6.1654 & 308.4667 & 9.3210 \\
\hline & Orange & 297.7823 & 5.2314 & 290.4657 & 4.389 & 303.2190 & 4.9934 & 303.2190 & 4.9934 \\
\hline & Papaya & 309.7473 & 10.1378 & 285.3457 & 6.169 & 288.4571 & 4.7719 & 302.1164 & 6.6686 \\
\hline & Pear & 327.0374 & 13.4954 & 347.2300 & 9.1904 & 364.5543 & 9.7458 & 386.7086 & 7.8160 \\
\hline \multirow{7}{*}{$\mathrm{WL}(\mathrm{mm} \times 100)$} & Kaki & 265.0754 & 7.8821 & 305.3591 & 7.2716 & 275.2533 & 3.2356 & 330.2429 & 12.7440 \\
\hline & Peach & 216.8050 & 3.0893 & 213.7436 & 2.9468 & 224.0542 & 3.4555 & 241.6478 & 4.3547 \\
\hline & Guava & 223.9357 & 4.7515 & 229.9878 & 4.5497 & 237.9060 & 7.7369 & 228.5739 & 4.1672 \\
\hline & Mango & 217.7722 & 3.4759 & 217.0837 & 5.3375 & 273.5795 & 4.4574 & 232.2204 & 7.0179 \\
\hline & Orange & 224.1770 & 3.9389 & 218.6689 & 3.3044 & 228.2697 & 3.7594 & 228.2697 & 3.7594 \\
\hline & Papaya & 233.1844 & 7.6331 & 214.8144 & 4.6448 & 217.1567 & 3.5930 & 227.4395 & 5.0208 \\
\hline & Pear & 246.2011 & 10.1609 & 261.4022 & 6.9196 & 272.6443 & 3.3970 & 291.1229 & 5.8849 \\
\hline \multirow{7}{*}{$\mathrm{WW}(\mathrm{mm} \times 100)$} & Kaki & 121.7164 & 3.6194 & 140.2137 & 3.3388 & 126.6077 & 1.4169 & 151.6395 & 5.8517 \\
\hline & Peach & 99.5517 & 1.4186 & 98.1456 & 1.3532 & 102.8802 & 1.5866 & 110.9586 & 1.9996 \\
\hline & Guava & 102.8257 & 2.1817 & 105.6046 & 2.0891 & 109.2405 & 3.5526 & 104.9553 & 1.9134 \\
\hline & Mango & 99.9955 & 1.5961 & 99.6792 & 2.4509 & 126.9796 & 1.9980 & 106.6299 & 3.2224 \\
\hline & Orange & 102.9366 & 1.8086 & 100.4073 & 1.5174 & 104.8159 & 1.7262 & 104.8159 & 1.7262 \\
\hline & Papaya & 107.0728 & 3.5049 & 98.6377 & 2.1327 & 99.7127 & 1.6499 & 104.4347 & 2.3054 \\
\hline & Pear & 113.0493 & 4.6657 & 120.0294 & 3.1772 & 125.2571 & 1.54134 & 133.6760 & 2.7022 \\
\hline \multirow{7}{*}{$\mathrm{TL}(\mathrm{mm} \times 100)$} & Kaki & 148.1967 & 4.4067 & 170.7181 & 4.0653 & 151.5739 & 1.9080 & 184.6304 & 7.1248 \\
\hline & Peach & 121.2101 & 1.7272 & 119.4982 & 1.6476 & 125.2627 & 1.9319 & 135.0993 & 2.4345 \\
\hline & Guava & 125.1964 & 2.6564 & 128.5802 & 2.5438 & 133.0074 & 4.3255 & 127.7894 & 2.3298 \\
\hline & Mango & 121.7509 & 1.9433 & 121.3655 & 2.9841 & 152.1212 & 2.3054 & 129.8283 & 3.9236 \\
\hline & Orange & 125.3315 & 2.2022 & 122.2520 & 1.8475 & 127.6199 & 2.1019 & 127.6199 & 2.1019 \\
\hline & Papaya & 130.3671 & 4.2674 & 120.0970 & 2.5969 & 121.4064 & 2.0088 & 127.1555 & 2.8070 \\
\hline & Pear & 137.6448 & 5.6808 & 146.1435 & 3.8686 & 152.4807 & 1.7686 & 162.7591 & 3.2901 \\
\hline \multirow{7}{*}{$\mathrm{HW}(\mathrm{mm} \times 100)$} & Kaki & 111.9855 & 3.3299 & 129.0043 & 3.0719 & 115.6423 & 1.3441 & 139.5165 & 5.3839 \\
\hline & Peach & 91.5930 & 1.3052 & 90.2992 & 1.2450 & 94.6553 & 1.4510 & 102.0881 & 1.8398 \\
\hline & Guava & 94.6051 & 2.0072 & 97.1620 & 1.922 & 100.5070 & 3.2686 & 96.5649 & 1.7605 \\
\hline & Mango & 92.0017 & 1.4685 & 91.7105 & 2.2548 & 115.6110 & 1.7451 & 98.1053 & 2.9648 \\
\hline & Orange & 94.7076 & 1.6641 & 92.3801 & 1.3961 & 96.4363 & 1.588 & 96.4363 & 1.5883 \\
\hline & Papaya & 98.5124 & 3.2247 & 90.7520 & 1.9623 & 91.7416 & 1.5179 & 96.0856 & 2.121 \\
\hline & Pear & 104.0116 & 4.2928 & 110.4338 & 2.9233 & 115.2350 & 1.4006 & 122.9894 & 2.4862 \\
\hline \multirow{7}{*}{ ID $(\mathrm{mm} \times 100)$} & Kaki & 58.9873 & 1.7541 & 67.9518 & 1.6182 & 60.8444 & 0.7068 & 73.4889 & 2.8360 \\
\hline & Peach & 48.2457 & 0.6875 & 47.5645 & 0.6558 & 49.8590 & 0.7690 & 53.7740 & 0.9690 \\
\hline & Guava & 49.8323 & 1.0574 & 51.1794 & 1.0124 & 52.9412 & 1.7217 & 50.8648 & 0.9273 \\
\hline & Mango & 48.4609 & 0.7735 & 48.3073 & 1.1878 & 60.6960 & 0.9931 & 51.6763 & 1.5616 \\
\hline & Orange & 49.8866 & 0.8764 & 48.6606 & 0.7355 & 50.7970 & 0.8365 & 50.7970 & 0.8365 \\
\hline & Papaya & 51.8907 & 1.6987 & 47.8026 & 1.0336 & 48.3239 & 0.7997 & 50.6123 & 1.1173 \\
\hline & Pear & 54.7873 & 2.2610 & 58.1696 & 1.5397 & 60.7008 & 0.7991 & 64.7839 & 1.3096 \\
\hline \multirow{7}{*}{$\begin{array}{l}\mathrm{V} \text { (proportion } \\
\text { of larvae that } \\
\text { emerged as flies) }\end{array}$} & Kaki & 0.6400 & 0.0748 & 0.7070 & 0.0452 & 0.4530 & 0.0780 & 0.6270 & 0.0859 \\
\hline & Peach & 0.7730 & 0.1108 & 0.7870 & 0.1143 & 0.8400 & 0.0340 & 1.0000 & 0 \\
\hline & Guava & 0.8930 & 0.03340 & 0.9070 & 0.0267 & 0.8130 & 0.0327 & 0.8270 & 0.0340 \\
\hline & Mango & 0.8670 & 0.0365 & 0.8670 & 0.0365 & 0.8670 & 0.0365 & 0.8270 & 0.0267 \\
\hline & Orange & 0.8670 & 0.0298 & 0.8800 & 0.0389 & 0.8670 & 0.0422 & 0.2130 & 0.0134 \\
\hline & Papaya & 0.6130 & 0.1062 & 0.5870 & 0.1062 & 0.7200 & 0.0389 & 0.8530 & 0.0490 \\
\hline & Pear & 0.8800 & 0.0327 & 0.8530 & 0.0442 & 0.7600 & 0.1147 & 0.8670 & 0.0600 \\
\hline
\end{tabular}


Table S2. Phenotypic Plasticity Index based on maximum and minimum medians $\left(\mathrm{PI}_{\mathrm{md}}\right)$ and Coefficient of Variation over the environments based on means $\left(\mathrm{CV}_{\mathrm{m}}\right)$ for each trait and population.

\begin{tabular}{|c|c|c|c|c|c|c|c|c|c|c|c|c|c|c|}
\hline & \multicolumn{2}{|c|}{ Viability } & \multicolumn{2}{|c|}{$\begin{array}{c}\text { Developmental } \\
\text { time }\end{array}$} & \multicolumn{2}{|c|}{ Wing length } & \multicolumn{2}{|c|}{ Wing width } & \multicolumn{2}{|c|}{ Thorax length } & \multicolumn{2}{|c|}{ Head width } & \multicolumn{2}{|c|}{$\begin{array}{l}\text { Inter-ocular } \\
\text { distance }\end{array}$} \\
\hline & PImd & $\mathrm{CVm}$ & PImd & $\mathrm{CVm}$ & PImd & $\mathrm{CVm}$ & PImd & $\mathrm{CVm}$ & PImd & $\mathrm{CVm}$ & PImd & $\mathrm{CVm}$ & PImd & $\mathrm{CVm}$ \\
\hline Lujeri & 0.231 & 0.22 & 0.202 & 0.11 & 0.202 & 0.11 & 0.202 & 0.11 & 0.202 & 0.11 & 0.202 & 0.11 & 0.189 & 0.11 \\
\hline Yokadouma & 0.231 & 0.24 & 0.291 & 0.15 & 0.291 & 0.15 & 0.281 & 0.15 & 0.291 & 0.15 & 0.281 & 0.15 & 0.291 & 0.15 \\
\hline Montecarlo & 0.347 & 0.22 & 0.210 & 0.14 & 0.210 & 0.11 & 0.215 & 0.11 & 0.209 & 0.11 & 0.209 & 0.11 & 0.207 & 0.11 \\
\hline Yuto & 0.800 & 0.22 & 0.340 & 0.17 & 0.340 & 0.17 & 0.340 & 0.17 & 0.340 & 0.17 & 0.339 & 0.17 & 0.340 & 0.17 \\
\hline
\end{tabular}

